УДК 378.1

DOI 10.23951/2307-6127-2020-1-93-101

\title{
ОБ ОТДЕЛЬНЫХ ПРИНЦИПАХ И ПРИЕМАХ ОБУЧЕНИЯ РУССКОМУ ЯЗЫКУ КАК ИНОСТРАННОМУ (НА ПРИМЕРЕ ИЗУЧЕНИЯ ИДИОМ, ОТРАЖАЮЩИХ ПОЛИТИЧЕСКУЮ ПРОБЛЕМАТИКУ)
}

\section{Хуа Ван}

\section{Шэньянский политехнический университет, Шэньян, Китай}

Рассматриваются принципы и приемы обучения русскому языку как иностранному в китайской студенческой аудитории, основанные на включении в процесс обучения иностранному языку материала, ориентированного на будущую профессиональную сферу (идиоматические выражения, отражающие политическую проблематику). На основе теоретического обобщения подходов китайских и российских лингвистов сформулированы основные подходы к выделению идиоматических выражений со стороны содержания (теоретическое исследование, исследование употребления) и со стороны методологии и лексикографии. Представлена характеристика ведущих методических принципов реализации языкового образования для китайских студентов: описаны приемы семантизации слов, способы лексикографической работы, описана логика работы в условиях специально организованной учебно-коммуникативной ситуации на всех этапах, представлен анализ работы с профессиональными текстами. Описаны механизмы учебной работы с идиоматическими выражениями, направленные на развитие совокупности иноязычной компетентности студентов китайских вузов. Экспериментальная апробация представленной совокупности приемов обучения русскому языку как иностранному в аудитории китайских студентов на продвинутом уровне показала свою эффективность.

Ключевые слова: языковая картина мира, русский язык как иностранный, коммуникация, идиоматические выражения, учебно-коммуникативная ситуачия.

Профессиональное становление специалиста - сложная задача, решение которой предъявляет к образовательному учреждению и студенту большие требования, так как современный студент уже на уровне обучения должен включаться в свое будущее профессиональное пространство, овладевать значительным объемом знаний и умений, которые позволят ему быть профессионалом в дальнейшем. В этих условиях изучение иностранного языка является важной и неотъемлемой составляющей, так как специалист в своей сфере деятельности должен уметь не только общаться со специалистами из аналогичных областей в своей стране и в других странах, но и уметь найти и переработать нужную информацию, представленную в глобальном мировом пространстве (публикации, материалы конференций и пр., в том числе опубликованные на иностранном языке). Владение иностранным языком на продвинутом уровне, специфическим профессиональным лексиконом на родном и иностранном языках, понимание логики профессионального мышления специалистов из других стран позволяют сформировать у студента постоянное состояние активного профессионального саморазвития. В связи с этим можно говорить о том, что в процессе профессионального становления (во время обучения в вузе) важно уделять изучению иностранных языков особое внимание, ориентируя данный процесс собственно предметным содержанием выбранной профессиональной сферы. Данное направление в изучении иностранных языков в отношении массового профессионального образования можно считать 
достаточно новым и мало разработанным; традиционно внимание уделялось общей языковой практике - умению изъясняться на изучаемом языке с носителем языка на общекультурные и бытовые темы, способность понять содержание разговора с использованием общеупотребительной лексики, способность читать и понимать основное содержание художественных текстов на языке оригинала, корректное использование словарей и переводчиков при необходимости. Несомненно, это важные знания и умения для современного образованного человека. Но вместе с тем считаем, что куда более важным с точки зрения профессионала нового поколения является не простое бытовое владение иностранным языком, а владение профессиональной лексикой, умением и навыками чтения научных источников, что, естественно, предъявляет новые требования к процессу изучения иностранного языка.

В центре нашего исследовательского внимания стоит подготовка студентов к политическому дискурсу в профессиональной и общественной среде. Обратим внимание, что юридические и политические языковые практики обеспечивают не только современную жизнь человека, но и являются специальной профессиональной сферой, отражающей как уникальные национальные особенности организации жизни, так и общечеловеческие характеристики, а поэтому и в сфере профессиональной юридической и политической деятельности внимание к современной международной практике, изучение великих цивилизационных достижений, несомненно, имеют большое значение в успешной деятельности современного профессионала. В данном контексте становится достаточно важным овладение языками великих цивилизаций, что сделает уровень профессиональной коммуникации более ярким, выразительным, образным, а вместе с тем и более точным.

Итак, почему все-таки настолько важно изучать иностранный язык (в нашем случае русский язык как иностранный) для того, чтобы стать хорошим профессионалом? Остановим свое внимание на той совокупности требований, которые сегодня предъявляются к современному уровню профессиональной подготовки. Прежде всего специалист, вне зависимости от будущей профессиональной сферы, должен обладать сформированным гуманистическим мировоззрением, а для этого должно быть сформировано понимание общечеловеческих ценностей, принципов равенства всех членов общества между собой (независимо от национальной принадлежности, религиозных и прочих взглядов), необходимо обладать в целом достаточной общекультурной компетентностью и эрудицией, не ограниченной рамками одной профессиональной сферы. Названные характеристики становятся существенными в создании целостного образа видения мира, в формировании человека и как личности, и как профессионала, обладающего современным профессиональным мышлением, способным реализовать свой потенциал в избранной сфере деятельности, демонстрируя высокий уровень и аналитических, и коммуникативных, и конструкторских/исследовательских/проектных/творческих умений и навыков. Отметим, что неслучайно в данной связи китайская образовательная практика вслед за российской акцентирует внимание не на формировании у учеников и студентов суммы знаний, умений и навыков, а компетенций, способствующих в том числе формированию механизмов профессионального саморазвития на долгосрочный период. При проведении нашего исследования вызвала интерес работа Н. С. Кузнецовой, в которой на основании анализа общеевропейских компетенций владения иностранным языком (разработаны Советом Европы) аргументированно утверждается, что «в области иностранного языка рассматриваются два вида компетенции: общие компетенции и коммуникативная языковая компетенция. Коммуникативная в свою очередь включает: а) лингвистический компонент; б) социолингвистический компонент; в) прагматический компонент» [1]. Ученые отмечают, что «конечным результатом усвоения содержания обучения признается формирование коммуникативной компетенции - способ- 
Хуа Ван. Об отдельных принципах и приемах обучения русскому языку как иностранному...

ности решать средствами изучаемого языка актуальные для личности учащегося и общества задачи общения в различных сферах: бытовой, учебной, производственной, культурной» $[1$, c. 273].

В практике Шеньянского политехнического университета, одного из крупнейших в Китайской Народной Республике, данной проблеме уделяется значительное внимание.

Каноническим является утверждение, что язык выступает средством, орудием всякой человеческой деятельности, но при этом язык - нечто большее. Современная позиция по отношению к языку значительно более широкая - язык рассматривается в контексте культуры народа - носителя языка, в контексте его культуры.

Не вызывает сомнений тот факт, что в семантической структуре слова содержится информация о системе ценностей народа - носителя языка, хранится культурный и исторический опыт народа, передается его особое «прочтение» окружающего мира. Всё это по-разному отпечатывалось в языке в разные периоды его истории и тем более по-разному представлено в разных диалектах и в общенациональном языке. Следует также четко осознавать, что слово является не только носителем знания, но и его источником, а потому и играет такую важную роль в познании и описании неязыковой действительности. Без его участия невозможна сама познавательная деятельность, не может осуществиться процесс мышления, и именно в этом смысле язык действительно является посредником между внутренним миром человека и объективно существующей реальностью.

А. Вежбицкая [2] справедливо полагает, что есть понятия, являющиеся фундаментальными для модели одного языкового мира и при этом отсутствующие в другом, а поэтому есть такие мысли, которые могут быть «подуманы» именно на этом языке, и даже есть такие чувства, которые могут быть испытаны только в рамках этого языкового сознания и никакому другому сознанию и менталитету не могут быть свойственны.

Понятие языковой картины мира играет значительную роль и в прикладных исследованиях, связанных с решением задач в рамках теорий искусственного интеллекта: сейчас стало понятно, что понимание компьютером естественного языка требует осмысления структурированных в этом языке знаний и представлений о мире, что связано зачастую не только с логическими рассуждениями или с большим объемом знаний и опыта, но и с наличием в каждом языке своеобразных метафор - не просто языковых, а метафор, представляющих собой формы мыслей и требующих правильных интерпретаций. Поэтому уходит в прошлое технология так называемого машинного (или построчного) перевода, современные переводчики предлагают выбор вариантов, который невозможно сделать корректно, если не владеешь специальными знаниями как в профессиональной сфере, так и в области культурологических знаний о стране изучаемого языка.

При выявлении ведущих методических принципов реализации языкового образования для китайских студентов мы обратили особое внимание на исследование М. Б. Будильницевой и Н. С. Новиковой, корректно описавших свое видение данного процесса на примере реализуемого ими курса «Русский язык и культура речи». Они выделили следующие принципы:

- адаптированное изложение общетеоретических тем курса;

- отбор иллюстративного лексического материала с учетом рамок лексического минимума I сертификационного уровня;

- аналитичность при изучении языкового материала;

- систематизация получаемых знаний;

- национальная ориентированность, т. е. учет специфики языковой системы родного языка (языка-посредника) и языковой картины мира носителей разных языков; 
- преимущественно практическая (коммуникативная) направленность обучения [3, c. 134].

В контексте нашего исследования мы опираемся на совокупность научных воззрений и в российской, и в китайской лингвистике. Обратим внимание, что в российской лингвистике идиомы и фразеологические обороты в большинстве исследований различаются и имеют как собственные, так и общие характеристики, в то время как в китайской научной литературе идиомы и фразеологизмы чаще всего рассматриваются как синонимы. Так, Хань Шо предлагает рассматривать фразеологические выражения как синонимические к идиоматическим, как устойчивое письменное словосочетание, имеющее две основные характеристики - целостность смысла и свертываемость конструкции. В исследовании другого китайского ученого, Шан Гуанчжуна, утверждается, что фразеологизм - это не только сложившееся словосочетание, но и продукция истории, кристаллизация познания. В продолжение данной картины видения отметим и позицию Мо Пэнлина, подчеркивающего неразрывную связь языка и культуры. Исследуя практику идиоматической культуры в целом (т. е. включая фразеологизмы), Мо Пэнлин отмечает содержание в ней богатой традиционной культуры и современную практику употребления идиом как культурный феномен [4].

Опираясь на совокупность представленных позиций китайских ученых, при проведении собственного исследования в условиях Шеньянского политехнического университета мы посчитали возможным рассматривать идиомы и фразеологизмы как имеющие общие элементы, рассматривать в китайской традиции терминологической синонимии, а сочетая актуальные позиции российских и китайских ученых, полагаем корректным изучать идиоматические выражения как со стороны содержания (теоретическое исследование, исследование употребления), так и со стороны методологии и лексикографии.

Идиоматические выражения являются значительным ресурсом языковой культуры, в полной мере содержащим языковую культурную информацию. Ниже опишем некоторые отдельные принципы и приемы обучения русскому языку как иностранному на продвинутом уровне на примере изучения идиом, отражающих политическую проблематику.

При работе с идиомами на политическую проблематику необходимо учитывать ряд важных приемов семантизации слов (как новых для студента, так и уже известных, но в непривычных или контекстных значениях). Во-первых, следует проводить систематическую работу по толкованию отдельных лексических единиц. Работа с толковыми словарями и переводчиками, изучение контекстных примеров позволяют внести коррекцию в толкование слова, сформировать навыки использования идиоматических выражений в текстах. Вместе с тем, учитывая принципиальные различия в структуре и логике русского и китайского языков, важно не только определять лексическое значение слова, но и проводить дополнительную работу по выявлению и усвоению его грамматического значения (так, если изучаемое слово - существительное, то необходимо определить его грамматический статус - род, склонение, образовать формы слова, просклоняв его, подобрать однокоренные слова), а также зафиксировать рамки его синтаксической употребляемости (составить словосочетания, простые предложения, в которых изучаемое слово будет выступать в различных синтаксических ролях, например существительное в роли подлежащего, дополнения, определения). И это второй важный прием работы над семантизацией новых слов, который можно обозначить как принцип структурно-семантической мотивации. Контекстная работа над новыми словами включает также перевод и толкование на двух языках - на родном для студента (китайском) и на изучаемом иностранном языке (русском), работа с уже известными лексемами, подбор синонимов, антонимов, использование текстов, ориентированных на восстановление пропусков слов. В качестве расширяющего данную работу приема стоит 
Хуа Ван. Об отдельных принципах и приемах обучения русскому языку как иностранному...

использовать различную иллюстративную и наглядную продукцию (видео, картинки, аудио - в зависимости от рассматриваемого слова). Перечень данных приемов не является законченным. В зависимости от слова могут быть включены и другие приемы, активно используемые в языковой практике изучения иностранных языков и привычные для студентов. Применение данных приемов как стартовых позволяет наиболее корректно определить в контексте содержание идиоматического выражения, значение которого отличается от суммы лексических значений входящих в него слов. На последующем этапе можно включать работу непосредственно с идиоматическими выражениями.

В процессе изучения идиом, ориентированных определенным направлением (в нашем случае - смыслами о политической и юридической практике, деятельности человека), эффективными себя показали специально организованные учебные ситуации, позволяющие реализовать достижение высоких образовательных ситуаций. Так, в исследовании Б. М. Джанжара и М. Х. Шхапанцевой, обосновавшем высокую значимость экстралингвистических параметров коммуникации, ориентированной будущей профессиональной сферой, описаны модельные варианты коммуникативной учебной ситуации, которая понимается учеными как динамическая система. Динамизм в данной сстуации выступает как оппозиция к статике и описывается ими через совокупность четырех взаимообусловленных факторов: «1) обстоятельств действительности (обстановка), в которых осуществляется коммуникация; 2) отношений между коммуникантами; 3) речевого побуждения; 4) реализации самого акта общения, создающего новые стимулы к речи. Каждая из указанных групп оказывает влияние на процесс общения: выбор темы и направление ее развития, отбор языковых средств, эмоциональную окраску речи, ее развернутость или свернутость и т. д.» [5, с. 23].

Мы согласны с авторами данного исследования в том, что участие студентов в приближенных к реальности ситуациях, специально организованных педагогом, позволяет не только оптимизировать процесс изучения иностранного языка, но и развить воображение, самостоятельность, мотивировать обучающихся на практическую востребованность владения иностранным языком не только «здесь и сейчас» (т. е. для отметки), но и «всегда» (т. е. приобретенные языковые навыки и компетентности выступают в роли ценностного компонента профессиональной состоятельности). В целом учебно-коммуникативная ситуация инициирует систематическое развитие иноязычной речи, формирует присваивание разговорных формул и клише изучаемого лексико-грамматического материала, способствует формированию профессионального мышления, выходящего за рамки получаемого образования (т. е. позволяет увидеть важные для себя компоненты профессионального становления и проявления, имеющиеся в зарубежной профессиональной практике, которые могут быть ими использованы в собственной). Опыт работы студентов в логике специально организованных учебных ситуаций позволяет научить студентов работать с научными текстами, изучать труды талантливых профессионалов прошлого. В нашем опыте включения учебных ситуаций при обучении русскому языку как иностранному мы отошли от принципа желательности преобладания диалоговой формы работы в процессе занятия, переместив внимание на формирование навыков работы со сложными профессиональными текстами. Это важно, на наш взгляд, именно с учетом того, что научные и другие информационные тексты имеют свой значительный потенциал для будущей профессиональной сферы студента, когда он войдет в профессиональный диалог с коллегами, в том числе из других стран.

Специально организованное пространство изучения русского языка как иностранного в китайской аудитории, как показывает наш опыт, особенно эффективен при сочетании использования различных методик. Так, включение аудиовизуальных и аудиальных методик 
помогает актуализировать не только звучание иноязычной речи, использование ставших традиционными и базовыми переводно-грамматического и сознательно-практического методов помогают усвоить все нормативные знания по изучаемому языку, а включение интенсивных методик (пользуясь терминологией доктора филологических наук, профессора Л. Ф. Крапивника [6], в их число включены суггестопедический, метод активизации, эмоционально-смысловой, ритмопедия, гипнопедия) способствует активизации психологических ресурсов личности студента. Последняя из названных групп методов обучения русскому языку как иностранному способствует последовательно включить студента в процесс понимания научных и учебных текстов профильного содержания, эффективно работать с текстовыми материалами, понимать, ретранслировать учебный материал в устной и письменной формах, формировать собственные тексты на изучаемом языке. Кроме названного исследования нами были использованы методические приемы, представленные в исследованиях А. Д. Юдина [7] и Т. Н. Персиковой [8], в которых описаны формы и методы обучения русскому языку как иностранному, позволившие интенсифицировать обучение русскому языку как иностранному китайских студентов. В частности, из трудов указанных авторов нами были взяты отдельные элементы работы с текстом.

Работа с идиоматическими выражениями направлена на развитие всей совокупности иноязычной компетентности студентов. Это позволяет добиться стройной и единообразной работы с текстами, когда каждый урок строится по одинаковой схеме, но отличается от других своим содержанием. Такой методический вариант позволяет студенту очень четко понимать логику занятия, очередность этапов учебной работы, что делает студента более уверенным и, соответственно, более результативным в процессе обучения.

Итак, первая часть задания содержит в себе работу над лексическим и семантическим значением текста, содержащего идиоматические выражения с контекстом политической проблематики. На этом этапе значительное внимание уделяется орфоэпической проработке, работе с вопросами по тексту, выяснению его содержания; особенное внимание уделяется той части, в которой содержатся собственно идиоматические выражения. На этом этапе предлагается работа с семантической стороной идиоматического выражения: важно его проанализировать, обсудить его тип и возможность дословного, контекстного или образного перевода, что невозможно сделать без привлечения культурологического аспекта, элементов знания не только культуры, но и истории, особенностей развития народа и страны изучаемого языка. В данной части исследования мы ориентировались на результаты, полученные В. С. Мордвинцевой [9], которые позволили проанализировать и структурировать причины возникновения фонетических сложностей, характерных для китайских студентов, а также развить методические приемы, позволяющие совершенствовать у них фонетические навыки в иноязычной речи.

На втором этапе происходит собственно лингвистическая практика, позволяющая выявить и отработать значительное количество аспектов русского языка - и собственно лексических, и морфологических, и синтаксических. Параллельное включение на данном этапе микроупражнений, содержащих работу над одной проблемой, позволяет решить и частные проблемы освоения русского языка как иностранного в китайской студенческой аудитории. Например, известно, что китайским студентам особенно сложно даются изменения формы слова в русском языке, а значит, включение в задание в качестве разминки склонения существительного или спряжения глагола, встречающихся в тексте, позволит актуализировать эти знания для студентов.

Другим обязательным элементом данной части работы с идиоматическими выражениями выступает работа с существительными. Мы исходим из того, что существитель- 
Хуа Ван. Об отдельных принципах и приемах обучения русскому языку как иностранному...

ные можно разделить на некоторые условные тематические группы, опираясь на ряд факторов: логической соотнесенности обозначаемого понятия, величины называемых ими предметов, количества, формы или конфигурации и др. Работа с этими группами позволяет развить у студентов совокупность владения языковыми средствами в полной мере.

На третьем этапе осуществляется работа с собственно идиоматическим контекстом: производится его системный анализ, перевод, подбираются синонимические и антонимические конструкции как из совокупности известных идиоматических и фразеологических выражений, так и без использования данных конструкций, выявляется уникальность смысла, передаваемая ими, и пр. Обратим внимание на исследование Ли Ли и Ли Шуцзинь [10], посвященное проблемам выявления национально-культурного контекста в русских и китайских фразеологизмах и осуществления корректного контекстного перевода с русского на китайский и с китайского на русский. Приведем несколько примеров перевода выражений. Так, в значительных по объему текстах студенты выделяют несколько устойчивых выражений, содержащих идиоматические смыслы, и осуществляют его перевод, выделяя разные контексты. Например, фразы «власть предержащие» и «власть имущие» могут быть переведены одним вариантом - 那些力量 (дословно понимается как «сила», «полномочие»), но в то же время контекстное понимание описывается как «обладающие властью», а выражение «рычаги власти» понимается как использование власти и переводится как 权力的杠杆.

В качестве итоговой части занятия нами предлагается составление устного высказывания или мини-сочинения по теме текста с обязательным использованием идиоматических конструкций.

Совокупность заданий по тексту с идиоматическим выражением, содержащим политическую проблематику, позволяет сочетать индивидуальную и групповые формы работы, сочетать устный и письменный способы освоения текста, а алгоритмизация работы может ориентировать студента на эффективное выполнение аналоговых заданий как в аудитории, так и формате выполнения домашних и самостоятельных заданий по схожей проблематике и по любому другому языковому материалу.

Итак, в процессе формирования иноязычной компетентности в области русского языка как иностранного для китайских студентов особенного внимания, на наш взгляд, заслуживают идиоматические выражения с акцентуацией на будущую профессиональную сферу студента. Это позволяет решать не только задачи иноязычного образования, но и задачи включения студента в интернациональную профессиональную сферу.

\section{Список литературы}

1. Кузнецова Н. С. Транскультурное обучение как способ формирования толерантности иностранных студентов, изучающих русский язык // Ученые записки Забайкальского государственного гуманитарно-педагогического университета им. Н. Г. Чернышевского. 2012. № 2 (43). С. 272-274.

2. Вежбицкая А. Сопоставление культур через посредство лексики и прагматики. М., 2001. 312 с.

3. Будильницева М. Б., Новикова Н. С. Интерфреренция и сопоставительный аспект в преподавании курса «Русский язык и культура речи» студентам-иностранцам // Вестник РУДН. Серия: Русский и иностранные языки и методика их преподавания. 2013. № 2. С. 129-135.

4. Хань Шо. Исследование и практика фразеологизмической культуры // Чанчжоу. Технологический институт. Вып. 33.

5. Джандар Б. М., Шхапацева М. Х. Учебная ситуация как основа коммуникативно-ситуативного обучения русскому языку как иностранному // Вестн. Адыгейского гос. ун-та. Серия 3: Педагогика и психология. 2012. № 2. С. 129-135.

6. Крапивник Л. Ф. Теория и методика преподавания русского языка как иностранного: учебно-методические материалы по дисциплине. Хабаровск, 2015. 59 с. 
7. Юдина А. Д. Русский язык как иностранный: наука без границ: учеб. пособие. URL: http://www.knigafund.ru/books/89793 (дата обращения: 23.10.2019).

8. Персикова Т. Н. Межкультурная коммуникация и корпоративная культура: учеб. пособие. М.: Логос, 2002. 124 с.

9. Мордвинцева В. С. Формирование слухопроизносительных навыков китайских студентов на материале регионально ориентированных диалогов // Филологические науки. Вопросы теории и практики. 2016. № 10-1 (64). С. 130-133.

10. Ли Ли, Ли Шуцзинь. Отражение национально-культурного аспекта в китайских и русских фразеологизмах // Научные ведомости Белгородского государственного университета. Серия: Гуманитарные науки. 2018. Т. 37, № 4. С. 542-553.

Хуа Ван, доцент, Шэньянский политехнический университет (ул. Наньпинчжунлу, 6, Новый район Хуньнань, г. Шэньян, Китай). E-mail: wanghuakzxy@yandex.ru

Материал поступил в редакциию 13.12.2019.

DOI 10.23951/2307-6127-2020-1-93-101

\section{ON THE INDIVIDUAL PRINCIPLES AND METHODS OF TEACHING RUSSIAN AS A FOREIGN LANGUAGE (BY THE EXAMPLE OF STUDYING IDIOMS REFLECTING POLITICAL ISSUES)}

\section{Hua Wang}

Shenyang Ligong University, Shenyang, PRC

The article considers the principles and methods of teaching Russian as a foreign language in the Chinese student audience, based on the inclusion in the process of teaching a foreign language of material focused on the future professional sphere (idiomatic expressions reflecting political issues). On the basis of the theoretical generalization of the approaches of Chinese and Russian linguists, the main approaches to the allocation of idiomatic expressions from the content (theoretical research, use research) and from the methodology and lexicography are formulated. The characteristic of the leading methodological principles of the implementation of language education for Chinese students is presented: the methods of semantization of words, methods of lexicographic work are described, the logic of work in a specially organized educational and communicative situation at all stages is described, the analysis of work with professional texts is presented. The mechanisms of educational work with idiomatic expressions aimed at the development of the set of foreign language competence of students of Chinese universities are described. Experimental approbation of the presented set of methods of teaching Russian as a foreign language in the audience of Chinese students at an advanced level has shown its effectiveness.

Keywords: language picture of the world, Russian as a foreign language, communication, idiomatic expressions, educational and communicative situation.

\section{References}

1. Kuznetsova N. S. Transkul'turnoye obucheniye kak sposob formirovaniya tolerantnosti inostrannykh studentov, izuchayu shchikh russkiy yazyk [Transcultural education as a way of forming tolerance of foreign students studying Russian]. Uchyenyye zapiski Zabaykal'skogo gosudarstvennogo gumanitarno-pedagogicheskogo universiteta im. N. G. Chernyshevskogo, 2012, no. 2 (43), pp. 272-274 (in Russian).

2. Vezhbitskaya A. Sopostavleniye kul'tur cherez posredstvo leksiki i pragmatiki [Comparison of cultures through vocabulary and pragmatics]. Moscow, 2001. 312 p. (in Russian).

3. Budil'nitseva M. B., Novikova N. S. Interferentsiya i sopostavitel'nyy aspekt v prepodavanii kursa "Russkiy yazyk i kul'tura rechi" studentam-inostrantsam [Interference and comparative aspect in teaching the course «Russian language and culture of speech» to foreign students]. Vestnik RUDN. Seriya: Russkiy i inostrannyye yazyki i metodika ikh prepodavaniya - RUDN Journal of Russian and Foreign Languages Research and Teaching, 2013, no. 2, pp. 129-135 (in Russian). 
Хуа Ван. Об отдельных принципах и приемах обучения русскому языку как иностранному...

4. Khan' Sho. Issledovaniye i praktika frazeologizmicheskoy kul'tury [Research and practice of phraseological culture]. Chanchzhou, Institute of Technology Publ. Vol. 33.

5. Dzhandar B. M., Shkhapatseva M. Kh. Uchebnaya situatsiya kak osnova kommunikativno-situativnogo obucheniya russkomu yazyku kak inostrannomu [Educational situation as a basis of communicative and situational teaching of Russian as a foreign language]. Vestnik Adygeyskogo gosudarstvennogo universiteta. Seriya 3: Pedagogika i psikhologiya - The Bulletin of Adyghe State University. Series 3: Pedagogy and Psychology, 2012, no. 2, pp. 129-135 (in Russian).

6. Krapivnik L. F. Teoriya i metodika prepodavaniya russkogo yazyka kak inostrannogo: uchebno-metodicheskiye materialy po distsipline [Theory and methods of teaching Russian as a foreign language: teaching materials on the discipline]. Khabarovsk, 2015. 59 p. (in Russian).

7. Yudina A. D. Russkiy yazyk kak inostrannyy: nauka bez granits [Russian as a foreign language: science without borders] (in Russian). URL: http://www.knigafund.ru/books/89793 (accessed 23 October 2019).

8. Persikova T. N. Mezhkul'turnaya kommunikatsiya i korporativnaya kul'tura: uchebnoye posobiye [Intercultural communication and corporate culture]. Moscow, Logos Publ., 2002. 124 p. (in Russian).

9. Mordvintseva V. S. Formirovaniye slukhoproiznositel'nykh navykov kitayskikh studentov na materiale regional'no-oriyentirovannykh dialogov [Formation of hearing-speaking skills of Chinese students on the material of regional-oriented dialogues]. Filologicheskiye nauki. Voprosy teorii i praktiki - Philological Sciences. Issues of Theory and Practice, 2016, no. 10-1 (64), pp. 130-133 (in Russian).

10. Li Li, Li Shutszin'. Otrazheniye natsional'no-kul'turnogo aspekta v kitayskikh i russkikh frazeologizmakh [Reflection of nationalcultural aspect in Chinese and Russian phraseological units]. Nauchnyye vedomosti Belgorodskogo gosudarstvennogo universiteta. Seriya: Gumanitarnyye nauki - Scientific bulletin of Belgorod State University. Humanities Sciences, 2018, vol. 37, no. 4, pp. 542-553 (in Russian).

Hua Wang, Shenyang Ligong University (Nanping Central Road, 6, Hunnan New District, Shenyang, PRC). E-mail: wanghuakzxy@yandex.ru 